\title{
The Architecture of Intelligent Career Prediction System based on the Cognitive Technology for Producing Graduates to the Digital Manpower
}

\author{
Pongsaton Palee ${ }^{1}$, Panita Wannapiroon ${ }^{2}$ \\ Division of Information and Communication Technology \\ for Education, Faculty of Technical Education \\ King Mongkut's University of Technology North Bangkok \\ Bangkok, Thailand
}

\author{
Prachyanun Nilsook ${ }^{3}$ \\ Dept. Information and Communication Technology \\ for Education, Faculty of Technical Education \\ King Mongkut's University of Technology North Bangkok \\ Bangkok, Thailand
}

\begin{abstract}
This research is a documentary research aimed at designing the architecture of the intelligent career prediction system based on the cognitive technology for producing graduates to the digital manpower. The research methods were divided into three phases: Phase 1, Composition Synthesis of Intelligent Career Prediction System. Phase 2, Intelligent Career Prediction System Architecture Designing based on the Cognitive Technology for producing graduates to the digital manpower. Phase 3, an assessment of the suitability of the architecture of the intelligent career prediction system based on the cognitive technology for producing graduates to the digital manpower. The architecture of the intelligent career prediction system by using the cognitive technology can be divided into three parts: 1) People involved in the architecture of the intelligent career prediction system consisting of five groups of related persons: students, staff, teachers, digital Enterprises, system administrator. 2) The architecture of the intelligent career prediction system consisting of four components: 1) User management, 2. Prediction Data Management, 3) Prediction Management system, 4) Prediction Display system, and cloud computing, an assessment of the suitability the architecture of the intelligent career prediction system based on the cognitive technology for producing graduates to the digital manpower by nine experts in the intelligent career prediction system and cognitive technology. The statistics used in the research are Mean and standard deviation. The evaluation results showed that the developed architecture was the most suitable, with the combined mean of 4.54, and the standard deviation was 0.49 .
\end{abstract}

Keywords-Architecture of intelligent career prediction system; cognitive technology; producing graduates; digital manpower

\section{INTRODUCTION}

Education is the process of developing people in society to be competent, the educational system is an important factor for the growth and development of the country, as information technology and digital technology has changed and developed more and more, the world is moving towards In the age of digital manpower generation, educational institutions, especially universities, play an important role in producing graduates that meet the modern labor market needs, universities need to adapt still include: 1) Curriculum development is up to date in modern times and more important to keep up with the technology that changes the way of life of the people in society. 2) Technology, teaching and learning tools, practical teaching for students to actually do their work, learn to work as a team and to solve immediate problems. 3) Educational personnel must act as coaches, provide guidance in order to make students the center of learning. 4) Universities should not only have a network of educational institutions but must build a network of partnerships with private businesses in order to create opportunities for students [1],[2].

Building the architecture of the intelligent career prediction system based on the cognitive technology for producing graduates to the digital manpower, to create a system for predicting further education of students who will enter the university, and also guide students who are about to graduate. Educators who are interested in pursuing a career in the digital Manpower [3], provide planning and preparation for such careers, resulting in the university developing a modern curriculum to accommodate the digital Manpower of Standardized, Reliable, Flexible Management of Learning Objectives, especially the intelligent career prediction system that can analyze digital Manpower professions, and also analyze what competencies students need in such professions to support the digital manpower in the upcoming Eastern Economic Corridor [4],[5] .

This architecture of the intelligent career prediction system based on the cognitive technology for producing graduates to the digital manpower presents a conceptual framework for the development of an information system model that combines the characteristics of the intelligent career prediction system with the cognitive technology to develop the next genius career prediction system.

\section{RESEARCH OBJECTIVES}

1) To synthesize the compositions of the architecture of the intelligent career prediction system based on the cognitive technology for producing graduates.

2) To design the architecture of the intelligent career prediction system based on the cognitive technology for producing graduates to the digital manpower.

3) To assess the suitability of the architecture of intelligent career prediction system based on the cognitive technology for producing graduates to the digital manpower. 


\section{RELATED WORKS}

Reference [6] The Digital career prediction system is the use of statistical algorithms data, and machine learning techniques to identify the likelihood of future results from historical data, predictive models use known results to develop or train. A model that can be used to predict values for different or new data, (for example, in our system, the target variable is a student's success in courses based on the estimated importance from a set of input variables, which is different from the descriptive model that helps in understanding what happened or a diagnostic model that helps in understanding important relationships and determining why and what happened.

Author(s) in [7],[8] Cognitive technology is the use of computers to simulate human learning, using cognitive technology learning algorithms to predict future results or to make different types of decisions under certain conditions. This allows the machine to understand the current situation on the basis of learning, enabling the machine to make informed decisions. Predictions, outcomes, or decisions will evolve as new information is received. Learning algorithms can be divided according to the learning process, the algorithm in the grouping (Classification) for learning to solve problems effectively (Supervised Learning) [9],[10]. The algorithm in grouping the exam level is divided into two steps: learning to create a template and the leveling of the exam to be graded, tested against an exam like a Training Data set, a process that uses the most common or similar search method to predict a data set that can be divided in any type of information. The Performance Model Assessment is the assessment of the model's ability to grade an exam's cognitive rating, through machine learning focused on decision-making or prediction, correct grading, a test method for comparing the model's performance to the performance of the exam's Cognitive rating, determined by its accuracy, from the Cognitive Rating [11].

The author in [12] Cloud computing is defined as a computing service or computer resource, covering the use of processors, memory, storage, and online systems from users to simplify the installation, administration, save time, reduce the cost of building the computer system, and the network itself. It is a behavior by using resources through the Internet. It is a processing method based on user needs. The user can specify a requirement to the system software, then the software requests the system to allocate resources and services to meet the user needs, which the system can increase and decrease the number of resources. Including offering services that fit the needs of users all the time, users can access various information systems via the Internet, users can manage system resources through the network, if the demand is greater, they can purchase additional services to increase their potential. The system without upgrading systems and computers, reduces costs and simplifies system administration and maintenance. The adoption of the intelligent career prediction system based on the cognitive technology on cloud computing to help to reduce costs, reduce time, simplify IT management, and when the demand grows, such as more users, better processing, more storage space, which can easily and conveniently expand the various resources of the Cloud system.

\section{Proposed Methodology}

The research method was divided into three phases according to the research objective.

Phase 1. Intelligent career prediction system model synthesis is the study of information about the composition synthesis of the intelligent career prediction system, the researcher has studied the document, the content analysis, and has synthesized nine related researches.

Phase 2: The Designing of Intelligent Career Prediction System Architecture Designing based on the Cognitive Technology for Producing graduates to the digital manpower, Intelligent Career Prediction System Architecture based on the Cognitive Technology for Producing graduates to the digital manpower by logical design to provide a model of the architecture of Intelligent career prediction system based on the Cognitive Technology for Producing graduates to the digital manpower, which incorporates the concept of architecture development (Conceptual Framework).

Phase 3: An assessment of the suitability of the architecture of the intelligent career prediction system based on the cognitive technology for producing graduates to the digital manpower is an assessment of suitability by using nine qualified persons.

\section{EXPERIMENTAL RESULTS AND DISCUSSIONS}

Phase 1: Results of composition synthesis of the intelligent career prediction system by using the research to synthesize the components of the intelligent career prediction system using the synthetic results table as shown in Table I.

Phase 2: The Architecture of the Intelligent career prediction system by using cognitive technology.

The architecture of the intelligent career prediction system by using the cognitive technology could be divided into three parts: 1) People involved in the intelligent career prediction system, 2) The architecture of the intelligent career prediction system, 3) Cloud computing as shown in Fig. 1 and Fig. 2.

A. People involved in the Architecture of the Intelligent Career Prediction System.

People involved in the architecture of the intelligent career prediction system consisted of five groups of stakeholders: students, staff, digital Enterprises, universities, administrators, with each group responsible as shown in Table II. 
TABLE I. SyNTHESIS TABLE OF THE INTELLIGENT CAREER PREDICTION SYSTEM MODEL FROM TABLE I, IT FOUND THAT THE INTELLIGENT CAREER PREDICTION SYSTEM CONSISTED OF 4 MAIN COMPONENTS

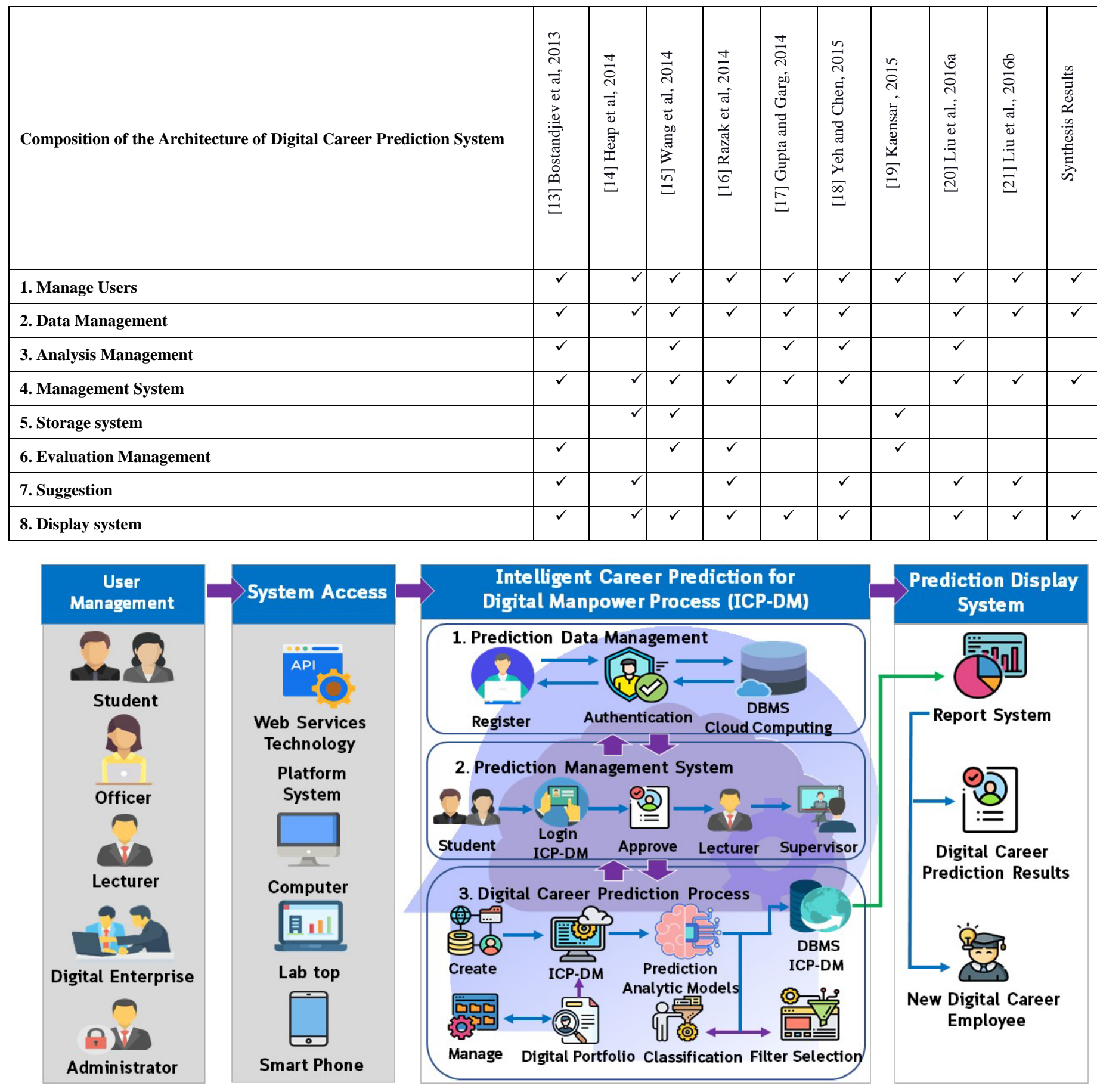

Fig 1. The Architecture of the Intelligent Career Prediction System based on the Cognitive Technology for Producing Graduates to the Digital Manpower. 
TABLE II. PERSONS INVOLVED IN THE ARCHITECTURE OF THE INTELLIGENT CAREER PREDICTION SYSTEM

\begin{tabular}{|c|c|}
\hline $\begin{array}{l}\text { Persons involved in } \\
\text { the architecture of } \\
\text { the intelligent career } \\
\text { prediction system }\end{array}$ & Responsibility \\
\hline 1. Student & $\begin{array}{l}\text { Personal Information Management, grades, } \\
\text { experience data, education, digital portfolios, } \\
\text { other data generated by the intelligent career } \\
\text { prediction system. } \\
\text { - } \quad \text { Check the results of the selection to work } \\
\text { - } \quad \text { Check the Enterprise's advice. }\end{array}$ \\
\hline 2. officer & $\begin{array}{ll}\text { - } & \text { Prepare career talent information } \\
\text { - } & \text { Prepare job position information } \\
\text { - } & \text { Check the information for accuracy }\end{array}$ \\
\hline 3. Teacher & $\begin{array}{l}\text { - } \quad \text { Prepare career talent information } \\
\text { - Prepare job position information and check the } \\
\text { information for accuracy }\end{array}$ \\
\hline 4. Digital Enterprise & $\begin{array}{ll}\text { - } & \text { Check the results of the selection to work } \\
\text { - } & \text { Check the information of job applicants. }\end{array}$ \\
\hline 5. Administrator & $\begin{array}{ll}\text { - } & \text { User Account Management } \\
\text { - } & \text { License Permission } \\
\text { - } & \text { Other job management }\end{array}$ \\
\hline
\end{tabular}

B. The Architecture of the Intelligent Career Prediction System the Architecture of the Intelligent Career Prediction System Consisted of the main Modules and Sub Modules as Shown in Table III

Phase 3: An Assessment of the suitability the architecture of the intelligent career prediction system based on the cognitive technology.

The Analysis of the suitability of the architecture of the intelligent career prediction system, the cognitive technology for producing graduates to the digital manpower by using descriptive statistics such as Mean and Standard Division, setting criteria for assessing suitability as Rating Scale Model, which has the criteria for determining the weight of the assessment into five levels according to the Linkert's Scale with the following criteria in Table IV.

- 5 represents the most suitable

- 4 represents very suitable

- 3 represents moderate suitable

- 2 represents less suitable

- 1 represents the least suitable

The Interpretation criteria to categorize the average score of suitability of the experts, there are scoring criteria for each level as follows:
TABLE III. THE MODULE OF THE ARCHITECTURE OF THE INTELLIGENT CAREER PREDICTION SYSTEM

\begin{tabular}{|c|c|c|}
\hline Main Modules & Sub Modules & Responsibility \\
\hline \multirow{3}{*}{$\begin{array}{l}\text { 1. User } \\
\text { Management }\end{array}$} & 1.1 Register & $\begin{array}{l}\text { Username and Password } \\
\text { First time registration, } \\
\text { user login, user must } \\
\text { enter Username and } \\
\text { Password. }\end{array}$ \\
\hline & 1.2 Edit Profiles & $\begin{array}{l}\text { Members change } \\
\text { information, personal } \\
\text { details such as changing } \\
\text { password, email address, } \\
\text { profile picture. }\end{array}$ \\
\hline & 1.3 License Permission & $\begin{array}{l}\text { License Permission to } \\
\text { different types of users } \\
\text { such as students, or } \\
\text { administrators. }\end{array}$ \\
\hline \multirow[b]{2}{*}{$\begin{array}{l}\text { 2. Prediction Data } \\
\text { Management }\end{array}$} & $\begin{array}{l}2.1 \text { Selection Prediction } \\
\text { Methods }\end{array}$ & $\begin{array}{l}\text { Show identification } \\
\text { values for career } \\
\text { prediction. }\end{array}$ \\
\hline & $\begin{array}{l}\text { 2.2 Cognitive } \\
\text { Technology }\end{array}$ & $\begin{array}{l}\text { Use the cognitive } \\
\text { technology to select the } \\
\text { rules of divination } \\
\text { according to the } \\
\text { conditions. }\end{array}$ \\
\hline \multirow{3}{*}{$\begin{array}{l}\text { 3. Prediction } \\
\text { Management } \\
\text { system }\end{array}$} & $\begin{array}{l}\text { 3.1 Evaluation } \\
\text { Examination }\end{array}$ & $\begin{array}{l}\text { Show a selection of } \\
\text { several career prediction } \\
\text { methods. }\end{array}$ \\
\hline & $\begin{array}{l}3.2 \text { Selection input file } \\
\text { processing }\end{array}$ & $\begin{array}{l}\text { Show a selection of files, } \\
\text { import career data to } \\
\text { predict. }\end{array}$ \\
\hline & $\begin{array}{l}\text { 3.3 Cognitive } \\
\text { Technology }\end{array}$ & $\begin{array}{l}\text { Use the cognitive } \\
\text { technology for choosing } \\
\text { the right predictions for } \\
\text { the profession. }\end{array}$ \\
\hline \multirow[t]{2}{*}{$\begin{array}{l}\text { 4. Prediction } \\
\text { Display System }\end{array}$} & $\begin{array}{l}\text { 4. View Position Digital } \\
\text { Career }\end{array}$ & $\begin{array}{l}\text { Show the results of job } \\
\text { titles or occupation } \\
\text { groups recommended to } \\
\text { users. }\end{array}$ \\
\hline & $\begin{array}{l}4.2 \text { Report Digital } \\
\text { Career statistics }\end{array}$ & $\begin{array}{l}\text { Show student statistics, } \\
\text { employment status of } \\
\text { graduates in 3D graph } \\
\text { format. }\end{array}$ \\
\hline
\end{tabular}

TABLE IV. ARCHITECTURAL EVALUATION CRITERIA USING LINKERT'S SCALE

\begin{tabular}{|l|l|}
\hline Mean frequency value & Meaning of values \\
\hline $4.50-5.00$ & represents to the most suitable \\
\hline $3.50-4.49$ & represents that is very suitable \\
\hline $2.50-3.49$ & represents moderate suitable \\
\hline $1.50-2.49$ & represents less suitable \\
\hline $1.00-1.49$ & represents the least suitable \\
\hline
\end{tabular}

An assessment of the suitability of experts in the intelligent career prediction system and the cognitive technology towards the architecture of the intelligent career prediction system by using the cognitive technology, the researcher had nine experts to do the assessment, and the suitability assessment results could be shown in Table V.

Table V shows Assessment Results of the suitability of the architecture of the intelligent career prediction system by using the cognitive technology. 


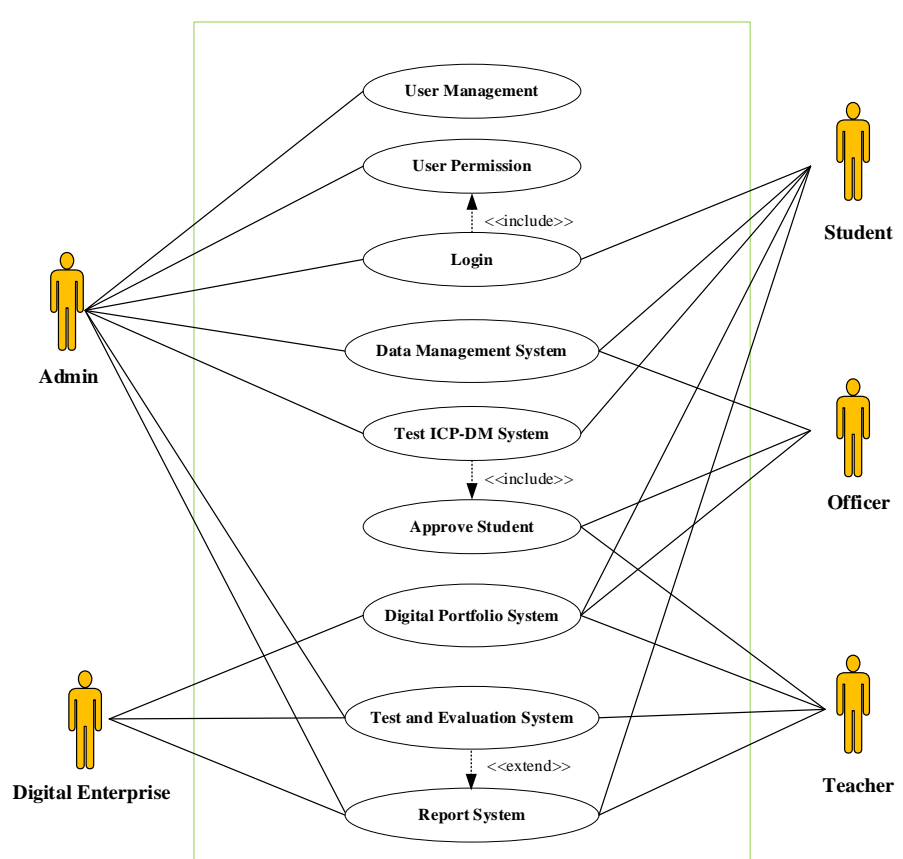

Fig 2. The Use Case Diagram of the Intelligent Career Prediction System User based on the Cognitive Technology for Producing Graduates to the Digital Manpower.

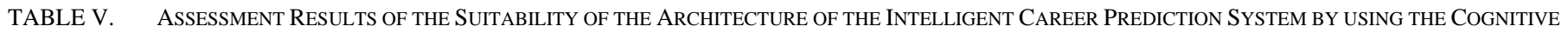
TECHNOLOGY

\begin{tabular}{|c|c|c|c|c|}
\hline \multirow[b]{2}{*}{ Details of the model } & \multicolumn{2}{|c|}{ Assessment results } & \multirow[b]{2}{*}{ Suitability level } & \multirow[b]{2}{*}{ Level } \\
\hline & $\overline{\boldsymbol{X}}$ & S.D. & & \\
\hline $\begin{array}{l}\text { 1. Principles and concepts used as the basis for the development of the } \\
\text { architecture of the intelligent career prediction system based on the cognitive } \\
\text { technology for graduate production. }\end{array}$ & 4.55 & 0.48 & Most suitable & \\
\hline \multicolumn{5}{|l|}{$\begin{array}{l}\text { 2. The architecture of the intelligent career prediction system based on the } \\
\text { cognitive technology }\end{array}$} \\
\hline \multicolumn{5}{|l|}{ 2.1 People involved in the intelligent career prediction system. } \\
\hline 2.1.1 Students & 4.60 & 0.55 & Most suitable & 3 \\
\hline 2.1.2 Teacher & 4.62 & 0.51 & Most suitable & 2 \\
\hline 2.1.3 Officer & 4.77 & 0.44 & Most suitable & 1 \\
\hline 2.1.4 Digital Enterprise & 4.44 & 0.33 & Highly suitable & 5 \\
\hline 2.1.5 Administrators & 4.55 & 0.48 & Most suitable & 4 \\
\hline \multicolumn{5}{|l|}{$\begin{array}{l}2.2 \text { The components of the intelligent career prediction system based on the } \\
\text { cognitive technology. }\end{array}$} \\
\hline 2.2.1 User Management & 4.55 & 0.48 & Most suitable & 3 \\
\hline 2.2.2 Prediction Data Management & 4.38 & 0.51 & Highly suitable & 4 \\
\hline 2.2.3 Prediction Management system & 4.33 & 0.55 & Highly suitable & 5 \\
\hline 2.2.4 Prediction Display system & 4.80 & 0.45 & Most suitable & 1 \\
\hline 3. Cloud computing & 4.60 & 0.55 & Most suitable & 2 \\
\hline $\begin{array}{l}\text { 4. The architecture of the Intelligent career prediction system based on the } \\
\text { cognitive technology for producing graduates to the digital manpower that can } \\
\text { be used for practical purposes. }\end{array}$ & 4.33 & 0.55 & Highly suitable & \\
\hline Summary of assessment items & 4.54 & 0.49 & Most suitable & \\
\hline
\end{tabular}


From Table V, assessment Results of the suitability of the architecture of the intelligent career prediction system were overall at the most level, with the mean of 4.51 and the standard deviation was 0.49 , which was in the range 0 to 1 , could be considered reliable data so it could be concluded that the experts with relatively similar opinions were most suitable.

\section{DISCUSSION}

This research is a documentary research, divided into two phases: component synthesis of the intelligent career prediction system and architectural design of the intelligent career prediction system by using the cognitive technology, data analysis by using content analysis techniques, research findings were in Fig. 1 and Fig. 2.

- The Intelligent career prediction system consisted of four components: 1) User management, 2) Prediction Data Management, 3) Prediction management system, 4) Prediction display system.

- The architecture of the intelligent career prediction system by using the cognitive technology could be divided into two parts: 1) those involved in the intelligent career prediction system, and 2) the architecture of the intelligent career prediction system consisted of four main modules: 1) User Management module consisted of 3 sub-modules: 1.1 Login module. (Register), 1.2 Edit Profiles Module, 1.3 License Permission. 2) Prediction Data Management module consisted of two sub-modules: 2.1 Selection Prediction methods, 2.2 Using the cognitive technology to select prediction rules to meet the conditions. 3) Prediction Management system module consisted of 3 sub-modules: 3.1 Evaluation data. Examination, 3.2 Selection input file processing, 3.3 Using the cognitive technology for selecting suitable prediction results for the profession. 4) Prediction display system module consisted of 2 sub-modules: 4.1 View position Digital Career, 4.2 Report Digital Career statistics, and then analyzed and designed the system and information for further research work.

\section{RESULT}

Assessing the suitability of the architecture of the intelligent career prediction system based on the cognitive technology for producing graduates to the digital manpower by nine experts in the intelligent career prediction system and the cognitive technology, the statistics used in the research are Mean and Standard Deviation, the Assessing results showed that the developed architecture was the most suitable, with the total mean of 4.51 and the standard deviation of 0.49 . The Cognitive Technology Classification processes uses data mining techniques to automatically group the items according to Bloom's taxonomy, which is consistent with the research of [22], [23], [24], [25] and [26] that grouped and classified based on Bloom's Revised Taxonomy.

\section{ACKNOWLEDGMENT}

Thanks to the experts in computer technology and digital manpower who have provided assistance in assessing, certifying, and providing suggestions for improving develop the Structural Equation Modeling for Digital Career Prediction Factor , thanks to National Research Council of Thailand, for supporting funding for this research, and Thanks to the advisor from King Mongkut's University of Technology North Bangkok, That provides advice and guides in organizing research in this time to be successful.

\section{REFERENCES}

[1] E-government office (2017). (Draft) The Digital Government Development Plan of Thailand 2017 - 2021. First Edition Bangkok: Bolliger \& Company (Thailand).

[2] Institute of professional qualifications (Public Organization) 2017. Occupational Standards Database, Professional Qualifications Software and Applications field. Retrieved from: https://tpqitest.tpqi.go.th/tpqi_sa/index.phppage=Pathway.php\&OCC=SWA.

[3] World Economic Forum (2016). “Global Challenge Insight Report -The Future of Jobs Employment, Skills and Workforce Strategy for the Fourth http://www3.weforum.org/docs/WEF_Future_of_Jobs.pdf.

[4] Eastern Economic Corridor Development Project. (2017) Action Plan for Education, Research and Technology Personnel Development. Retrieved from https://www.eeco.or.th.

[5] Ministry of Digital Economy and Society. (2016). Digital Economy and Society Development Plan. First edition, Bangkok:(Electronic $\begin{array}{lllll}\text { document). } & \text { Retrieved } & 14 & \text { October } & 2020 .\end{array}$ From https://www.dga.or.th/th/profile/2008.

[6] Kalyankar, G. D., Poojara, S. R., \& Dharwadkar, N. V. (2017). Predictive Analysis of Diabetic Patient Data Using Cognitive Technology and Hadoop.2017 International Conference on I-SMAC (IoT in Social, Mobile, Analytics and Cloud) (I-SMAC 2017), 619624. https://doi.org/10.1109/I-SMAC.2017.8058253.

[7] F. Mart, L. Contreras-ochando, M. Kull, and N. Lachiche, “CRISP-DM Twenty Years Later: From Data Mining Processes to Data Science Trajectories,” vol. 4347, no. c, 2019, doi: 10.1109/TKDE.2019.2962680.

[8] W. Puarungroj, N. Boomsirisumpun, P. Pongpatrakant, and S. Phromkot, "A preliminary Implementation of Data Mining Approaches for Predicting the Results of English Exit Exam,” in International Conference on Information Technology (INCIT), 2017, vol. 53, no. 9, pp. 1689-1699, doi: 10.1017/CBO9781107415324.004.

[9] C. Wongwatkit, “An Online Web-based Adaptive Tutoring System for University Exit Exam on IT Literacy," Int. Conf. Adv. Commun. Technol. ICACT, vol. 2019-Febru, pp. 563-568, 2019, doi: 10.23919/ICACT.2019.8701994.

[10] J. Flowers, "The problem in technology education (A definite article)," J. Technol. Educ., vol. 21, no. 2, pp. 10-20, 2010, doi: 10.21061/jte.v21i2.a.2.

[11] N. Ketui, W. Wisomka, and K. Homjun, "Using classification data mining techniques for students performance prediction,” ECTI DAMTNCON 2019 - 4th Int. Conf. Digit. Arts, Media Technol. 2nd ECTI North. Sect. Conf. Electr. Electron. Comput. Telecommun. Eng., pp. 359-363, 2019.

[12] Akrima Boonyoo and Nopadon Kaewbanphot. 2015. What is Cloud computing? Library and Information Center, Science and Technology Department of Science Service. Retrieved from: http://lib3.dss.go.th/fulltext/dss_knowledge/bsti-6-2558-cloud.pdf.

[13] Bostandjiev, S., O’Donovan, J., Höllerer, T., 2013. LinkedVis: exploring social and Semantic carrer recommendations. Proceedings of the 2013 International. Conference on Intelligent User Interfaces. ACM, pp. 107116.

[14] Heap, B., Krzywicki, A., Wobcke, W., Bain, M., Compton, P., 2014. Combining career progression and profile matching in a job recommender system. In: Pacific Rim International Conference on Artificial Intelligence. Springer International Publishing, pp. 396-408.

[15] Wang, Y., Zhang, X., Nan, L., Wang, D., 2014. Digital Career recommendation based on student achievement mining in vocational skill training. In: $201411^{\text {th }}$ International Conference on Fuzzy Systems and Knowledge Discovery (FSKD). IEEE, pp. 686-691.

[16] Razak, T.R., Hashim, M.A., Noor, N.M., Halim, I.H.A., Shamsul, N.F.F., 2014. Career path recommendation system for UiTM Perlis 
students using fuzzy logic. In: 2014 5th International Conference on Intelligent and Advanced Systems (ICIAS), IEEE.

[17] Gupta, A., Garg, D., 2014. Applying data mining techniques in job recommender system for considering candidate job preferences. In: 2014 International Conference on Advances in Computing, Communications and Informatics (ICACCI). IEEE, pp. 1458-1465.

[18] Yeh, C.T.D., Chen, T.M., 2015. Ubiquitous job recommendation system for graduates in Taiwan. Int. J. Electron. Commerce Stud. 6 (1), 127136.

[19] Kaensar, C., 2015. Design of personal job recommendation framework on smartphone platform. World Acad. Sci. Eng. Technol. Int. J. Comput. Electr. Autom. Control Inf. Eng. 9 (12), 2315-2319.

[20] Liu, R., Ouyang, Y., Rong, W., Song, X., Xie, W., Xiong, Z., 2016a. Employer oriented recruitment recommender service for university students. In: International Conference on Intelligent Computing, Springer International Publishing.

[21] Liu, R., Ouyang, Y., Rong, W., Song, X., Tang, C., Xiong, Z., 2016b. Rating prediction based job recommendation service for college students. In: International Conference on Computational Science and Its Applications. Springer International Publishing, pp. 453-467.
[22] C. Paiwithayasiritham, P. Makmee, and K. Mingsiritham, "The Development of a training program for basic education school teachers on developing the higher level learning assessment methods," Veridian E-Journal, Silpakorn Univ., vol. 6, no. 1, pp. 904-913, 2013.

[23] U. Shafique and H. Qaiser, "A Comparative Study of Data Mining Process Models (KDD, CRISP-DM and SEMMA),” Int. J. Innov. Sci. Res., vol. 12, no. 1, pp. 217-222, 2014.

[24] C. Paiwithayasiritham, P. Makmee, and K. Mingsiritham, "The Development of a training program for basic education school teachers on developing the higher level learning assessment methods," Veridian E-Journal, Silpakorn Univ., vol. 6, no. 1, pp. 904-913, 2013.

[25] M. H. Ying, S. H. Huang, and L. R. Wu, "An item selection strategy based on association rules and genetic algorithms,” 2009 4th Int. Conf. Innov. Comput. Inf. Control. ICICIC 2009, pp. 1040-1044, 2009.

[26] M. Mohammed and N. Omar, "Question classification based on Bloom's Taxonomy using enhanced TF-IDF,” Int. J. Adv. Sci. Eng. Inf. Technol., vol. 8, no. 4-2, pp. 1679-1685, 2018. 